\title{
A Study on the Infection Exposure Defense Environment, Infection Recognition, and Infection Prevention Behavior of Nursing Assistants
}

\author{
Mi-Jin Kim ${ }^{1}$, Gye-Young Shin ${ }^{2}$ and Young-Soon $\mathrm{Choi}^{3 *}$ \\ ${ }^{1,2}$ Department of Nursing, Shinhan University, 95, Hoam-ro, Uijeongbu-si, Gyeonggi- \\ do, 480-857, Republic of Korea \\ ${ }^{3}$ Department of Nursing, Kangwon National University, Samcheck-si, Gangwon-do, \\ 25949, Republic of Korea \\ 1'kimijin29@daum.net, 2joycey@naver.com,3ysc615@kangwon.ac.kr
}

\begin{abstract}
This study is a descriptive research study to investigate Infection Exposure Defense environment, infection awareness, and performance of infection prevention of nursing assistants. The data was collected from October 1 to October 31, 2018 with the consent of the subjects, and 198 participants were used in the final analysis. The questionnaire consisted of demographic characteristics, defense environment for infection exposure, infection awareness, and prevention of infection. Collected data were analyzed using descriptive statistics, $t$-test and ANOVA using SPSS 21.0 statistical program. As a result of this study, the infection protection environment was statistically significant for hospital size, bed size, infection exposure management guideline, education of countermeasures for infection incidents, dedicated nurses, regular infection control education, and experience of injury by instruments or needles. There was a statistically significant difference in the perception of infection exposure in the placement of dedicated nurses and regular infection management education, and the performance of infection prevention activities was statistically significant in the placement of dedicated nurses. Therefore, continuous support from hospital managers and administrators to improve the environment for prevention of infection is necessary, and various systematic training methods should be developed for the site.
\end{abstract}

Keywords: Infection exposure, Defense environment, Infection recognition, Infection prevention behavior, Nurse assistant

\section{Introduction}

In hospitals, medical workers working in special circumstances have many opportunities to interact with infected patients and carriers, they are a high-risk group of infections that are frequently exposed to various samples from patients, the environment of contaminated medical devices, and the contaminated air [1].

Hospital infections were first mentioned in "In-hospital Infections" published by the Hospital Association in 1968. Since 1970, the Public Health Service has defined infections that

Article history:

Received (March 13, 2019), Review Result (June 24, 2019), Accepted (September 6, 2019) 
have not been symptomatic at the time of hospital admission and are not latent to infectious diseases, as infections occurring after hospitalization or discharge[2].

The study of hospital infections in Korea is estimated to have started since the 1980s. The Korean Hospital Association has implemented the hospital standardization review system since 1981 and recognized the importance of hospital infection management and included it as a main evaluation item [3].

Incidence of hospital infections can be a problem for the safety of patients and the safety of health workers, it is a cause of prolonged hospital stay, death, prevalence and burden of medical expenses, and is regarded as an important evaluation index for the quality of nursing [4][5].

Effective infection control should be systematically and systematically managed through education to patients, caregivers, medical personnel and other hospital staff based on hospital infection control guidelines [4].

Referring to previous research related to hospital infection management subject for nursing personnel, a study confirming the awareness and practice of infection control for nursing workers in geriatric nursing hospitals [3], a study confirming the incidence of infection according to the size of long-term care facilities and the characteristics of nursing personnel[6]. Domestic research on the recognition and performance of hospital infection control [4], the study on infection control of visiting nurses in public health centers [7], and the studies on infection control of 119 paramedics [8], but the research on nursing assistants is insufficient.

The purpose of this study is to examine the protective environment, infection awareness, and performance of infection prevention in nursing assistants, it was attempting to utilize as a basis for effective infection control system that can prevent infection exposure of nursing assistants required for the efficient operation and management.

\section{Research method}

\subsection{Research subject}

This study subject is a nursing assistant who visited the training center of the Nursing Assistants Association Training Center in G-do to take conservative education, and the subjects were nursing assistants who received a description of the study and agreed in writing.

The number of subjects was extracted using $G$ power 3.1.9.2 program, and when the significance level was 0.05 , the effect size 0.2 , and the power 0.9 , the number of samples required for correlation study was 175 . Although 200 people were excluded in consideration of the dropout rate of $10 \%$, the final 198 parts were excluded, except for two parts with insufficient answers.

\subsection{Data collection}

The data collection period of this study was from January 1, 2019 to February 28, 2019. Before the data collection, explain the purpose of this study, how to collect data, and how to dispose of the data. After receiving the survey was conducted. When the questionnaire was withdrawn during the questionnaire, there was no disadvantage. The average time for completing the questionnaire was about 10 minutes.

\subsection{Data analysis}

The collected data were analyzed using the SPSS 21.0 program. The details are as follows. The general characteristics of the subjects were frequency analysis by number and percentage. 
The subject's Infectious exposure defense environment, infection exposure awareness, and infection exposure pevention behavior are analyzed by average, standard deviation. The t-test and ANOVA of infectious exposure defense environment, infection exposure awareness, and infection exposure pevention behavior according to the general characteristics of the subjects were analyzed by t-test and Scheffe's test.

\section{Research results}

\subsection{General characteristics of subjects}

The subjects of this study were 197 women $(99.5 \%)$ and 1 male $(0.5 \%)$, the marital status was 163 married (82.3\%) and 35 unmarried (17.7\%). The level of education was $143(72.2 \%)$ graduated from high school, and the degree of education at university or higher was $55(28.8 \%)$. The size of hospital was the highest with 115 people $(58.1 \%)$ working in the clinics. Their average age was $41.33( \pm 8.35)$ years, their current career was $64.90( \pm 70.83)$ months and their total career was $182.76( \pm 137.77)$ months [Table 1].

Table 1. General characteristics of subjects

\begin{tabular}{|c|c|c|c|}
\hline Variables & Categories & \multicolumn{2}{|c|}{$\mathrm{n}(\%)$ or $\mathrm{M} \pm \mathrm{SD}$} \\
\hline \multirow{2}{*}{ Gender } & Male & 1 & $(0.5)$ \\
\hline & Female & 197 & $(99.5)$ \\
\hline \multirow{2}{*}{ Marrital status } & Unmarried & 35 & $(17.7)$ \\
\hline & Married & 163 & $(82.3)$ \\
\hline \multirow{4}{*}{ Education } & High school graduate & 143 & $(72.2)$ \\
\hline & Associate degree & 36 & $(18.2)$ \\
\hline & Bachelor's degree & 17 & $(8.2)$ \\
\hline & Above master & 2 & $(1.0)$ \\
\hline \multirow{6}{*}{ Hospital size } & Local (include clinic) & 115 & $(58.1)$ \\
\hline & Below 100 bed hospital & 13 & (6.6) \\
\hline & 101 200 bed hospital & 21 & $(10.6)$ \\
\hline & 201 400 bed hospital & 18 & $(9.1)$ \\
\hline & Over 401 bed hospital & 7 & (3.5) \\
\hline & The others & 24 & $(12.1)$ \\
\hline Age (year) & - & 41.33 & \pm 8.35 \\
\hline Hospital experience (month) & - & 117.86 & \pm 81.59 \\
\hline Present work place experience (month) & - & 64.90 & \pm 70.83 \\
\hline Total hospital experience (month) & - & 182.76 & \pm 137.77 \\
\hline
\end{tabular}

\subsection{Infection-related characteristics of subject}

$106(53.5 \%)$ responded that there was an exposure control guideline, $145(73.2 \%)$ were aware of what to do when exposed to an infection. 51 (25.8\%) responded that they had been 
assigned a dedicated nurse, $69(34.8 \%)$ received regular infection management training. 82 (41.4\%) had been exposed to infectious diseases during their work, and 40 (20.2\%) of them were infected with influenza. There were $139(70.2 \%)$ who had been injured by the instruments or needles they used, and they reported that they experienced damage from 1 to 12 times a year. $78(39.4 \%)$ said they were injured when cleaning up after treatment, and $131(66.2 \%)$ were injured by needles, the reason for the injury was the lack of time in $67(33.8 \%)$ and the next was due to inattention $62(31.3 \%)$. The most common reason for not performing infection prevention activities was 'hassle' $80(40.4 \%))$ [Table 2].

Table 2. Infection related characteristics of subjects $(\mathrm{N}=198)$

\begin{tabular}{|c|c|c|c|}
\hline Variables & Categories & \multicolumn{2}{|c|}{$\mathrm{n}(\%)$} \\
\hline \multirow{2}{*}{ Infection Control Guide } & Yes & 106 & $(53.5)$ \\
\hline & No & 92 & $(46.5)$ \\
\hline \multirow{2}{*}{ Know how to manage infections } & Yes & 145 & $(73.2)$ \\
\hline & No & 53 & $(26.8)$ \\
\hline \multirow{2}{*}{$\begin{array}{l}\text { Placement of dedicated nurses for } \\
\text { infection }\end{array}$} & Yes & 51 & $(25.8)$ \\
\hline & No & 147 & $(74.2)$ \\
\hline \multirow{2}{*}{ Regular Infection Control Training } & Yes & 69 & $(34.8)$ \\
\hline & No & 129 & $(65.2)$ \\
\hline \multirow{2}{*}{$\begin{array}{c}\text { Experience exposure to infectious } \\
\text { diseases }\end{array}$} & Yes & 82 & $(41.4)$ \\
\hline & No & 116 & $(58.6)$ \\
\hline \multirow[t]{5}{*}{ Exposed infectious disease } & Tuberculosis & 15 & (7.6) \\
\hline & Viral hepatitis & 20 & $(10.1)$ \\
\hline & Influenza & 40 & $(20.2)$ \\
\hline & Other & 11 & $(5.5)$ \\
\hline & No experience & 112 & $(56.6)$ \\
\hline \multirow{2}{*}{$\begin{array}{l}\text { Wound experience by mechanism and } \\
\text { needle }\end{array}$} & Yes & 139 & $(70.2)$ \\
\hline & No & 59 & $(29.8)$ \\
\hline \multirow[t]{6}{*}{ Average number of wounds per year } & 0 & 59 & $(29.8)$ \\
\hline & 1 & 69 & $(34.8)$ \\
\hline & 2 & 34 & $(17.2)$ \\
\hline & $3-5$ & 28 & $(14.1)$ \\
\hline & $6-10$ & 7 & $(3.5)$ \\
\hline & $>10$ & 1 & $(0.5)$ \\
\hline \multirow[t]{6}{*}{ Time of injury } & Before treatment & 23 & $(11.6)$ \\
\hline & During treatment & 15 & (7.6) \\
\hline & After treatment & 78 & (39.4) \\
\hline & When washing utensils & 14 & $(7.1)$ \\
\hline & Other & 9 & $(4.5)$ \\
\hline & No experience & 59 & $(29.8)$ \\
\hline \multirow[t]{3}{*}{ Mainly wounding apparatus } & Needle & 131 & $(66.2)$ \\
\hline & Blade & 3 & $(1.5)$ \\
\hline & The other & 5 & $(2.5)$ \\
\hline
\end{tabular}




\begin{tabular}{|c|c|c|c|}
\hline \multirow{4}{*}{ Reason for wound } & No experience & 59 & $(29.8)$ \\
\hline \multirow{4}{*}{ Reasons not to prevent infection } & Running out of time & 67 & $(33.8)$ \\
\cline { 2 - 4 } & Wear no protective equipment & 5 & $(2.5)$ \\
\cline { 2 - 4 } & Carelessness & 62 & $(31.3)$ \\
\cline { 2 - 4 } & Other & 2 & $(1.0)$ \\
\cline { 2 - 4 } & No experience & 62 & $(31.3)$ \\
\cline { 2 - 4 } & Costly & 22 & $(11.1)$ \\
\cline { 2 - 4 } & Hassle & 80 & $(40.4)$ \\
\cline { 2 - 4 } & Longer medical treatment time & 37 & $(18.7)$ \\
\cline { 2 - 4 } & Not interested & 14 & $(7.1)$ \\
\cline { 2 - 4 } & Other & 30 & $(15.2)$ \\
\hline
\end{tabular}

3.3. Subject's infectious exposure defense environment, infection exposure awareness, and infection exposure prevention behavior score

The infection exposure environment averaged 3.15 points out of 5 points, the average exposure awareness was 4.63 points out of 5 points, and the performance of infection prevention was 4.66 points out of 5 points [Table 3].

Table 3. Average score of Infection exposure defense environment, awareness of infection exposure, and performing infection prevention behavior

\begin{tabular}{|c|c|c|c|}
\hline Variables & Mean & \pm SD & Range \\
\hline Infection exposure defense environment & 3.15 & \pm 1.02 & $0 \sim 5$ \\
\hline Infection exposure awareness & 4.63 & \pm 0.44 & $0 \sim 5$ \\
\hline Performing infection prevention behavior & 4.66 & \pm 0.43 & $0 \sim 5$ \\
\hline
\end{tabular}

\section{Discussion \& conclusion}

The purpose of this study was to examine the infectious exposure defense environment, infection exposure awareness, and infection exposure prevention behavior of nursing assistants. And then attempts were made to use the basic data necessary for the operation and effective management of effective infection control systems to prevent infection exposure of nursing assistants. Based on the study results to the following suggestions such.

First, continuous attention and efforts by hospital managers are needed to improve the performance of infection prevention activities. first of all, it is necessary to arrange dedicated nursing staff. Second, follow-up studies are needed to confirm the relationship between infectious exposure defense environment, infection exposure awareness, and infection exposure prevention behavior of nursing assistants. Third, it is necessary to repeat research including various influence factors to improve the performance of infection exposure prevention.

\section{References}


A Study on the Infection Exposure Defense Environment, Infection Recognition, and Infection Prevention Behavior of Nursing Assistants

[1] J. Y. Ahn, Y. M. Lee, and S. H. Song, "A study on performance level for universal precautions on blood-borne infections among nurses in hospitals," Korean Journal of Nursing Education, vol.16, no.1, pp.92-100, (2010) DOI: 10.5977/JKASNE.2010.16.1.092

[2] K. H. Lee, "The relation of medical laboratory technologist cognition, eromance and psychological empowerment with nosocomial infection control in medical laboratory technologist," M.S. thesis, Kyungpook National University, pp.37, (2017)

[3] G. H. Lee and J. H. Lee, "Perception and practice of hospital infection control of nursing staff depending on the supplementation of nurses in long-term care hospitals," Journal of Occupational Health Nursing, vol.21, no.3, pp.308-316, (2012) DOI: 10.5807/kjohn.2012.21.3.308

[4] M. Y. Gang, "A study on the performance of the management of nosocomial infection of the hospital nurses," M.S. thesis, Kongju National University, pp.87, (2010)

[5] Kallel H., Bahou M. Ksibi H., Dammak H., Chelly H., Hamida C. B., Chaari A., Rekik N., and Bouaziz M. "Prevalence of hospital-acquired infection in a Tunisian hospital," Journal of Hospital Infection, vol.59, no.4, pp.343-347, (2005) DOI: 10.1016/j.jhin.2004.09.015

[6] M. H. Go, "Long-term care facility size and nursing personnel characteristics, bedsores of recipients, urinary tract infections," M.S. thesis, Kyungpook National University, pp.47, (2019)

[7] K. N. Kim and J. J. Oh, "Perception of Importance and Performance in the infection control of visiting nursing personnel in public health centers," Korean Journal of Community Nursing, vol.11, no.2, pp.389-398, (2000).

[8] W. M. Jo, "A level of awarenes and practice of 119 Emergency Medical Technician about infection control," M.S. thesis, Kongju National University, pp.63, (2008) 